\title{
El discurso de los emigrados peruanos en Chile: El Intérprete, 1836-1837
}

\author{
César Puerta Villagaray \\ Universidad Nacional Mayor de San Marcos \\ < cpuertav@unmsm.edu.pe >
}

\section{RESUMEN}

El objetivo del artículo es estudiar el discurso político elaborado por los emigrados peruanos en Chile entre 1836 y 1837 . Se busca comprender la forma cómo los emigrados justificaron tanto su lucha contra la Confederación Perú-Boliviana como el apoyo que brindaron a la intervención militar chilena. En ese sentido se plantea que el discurso de los emigrados peruanos formó parte de una lucha política, en la cual coexistieron en permanente tensión dos ideales republicanos: el patriótico cívico y el nacionalista.

PALABRAS CLAVE: Confederación Perú-Boliviana, emigrados, discurso político, historia del Perú republicano

\section{The political discourse of the Peruvian emigrants in Chile: El Intérprete, 1836-1837}

ABSTRACT

The objective of the article is to study the political discourse elaborated by the Peruvian emigres in Chile between 1836 and 1837. The aim is to understand how the emigrants justified their struggle against the Peru-Bolivia Confederation and the support they offered to the intervention Chilean military. In this sense, it is argued that the discourse of the Peruvian emigrants was part of a political struggle, in which two republican ideals coexisted in permanent tension: the civic patriotic and the nationalist.

KEYWORDS: Peru-Bolivia Confederation, emigrants, political discourse, history of republican Peru 
«[...] los emigrados no se enrolan en las filas que combaten al Perú, sino en las filas que combaten al que ha combatido y oprime al Perú, se sigue que el Perú no tendrá que perdonarles, sino que agradecerles». El Intérprete, número 19, 19 de octubre de 1836 , p. 1.

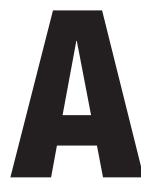
mediados de 1837, en la localidad de Quillota y en la ciudad de Valparaíso, ocurrieron varios acontecimientos que serían determinantes para definir la tensa relación entre los diversos grupos de emigrados peruanos y las autoridades del gobierno chileno. Estos acontecimientos, conocidos como el Motín de Quillota, empezaron en esta localidad el 3 de junio de 1837 con la sublevación de un grupo de militares chilenos liderados por el coronel José Antonio Vidaurre (1798-1837). Ese día, los insurrectos secuestraron al ministro de Guerra y Marina Diego Portales (1793-1837) y tres días después, el 6 de junio, lo asesinaron. El mismo día de la muerte de Portales, se desarrolló en Valparaíso la Batalla del Barón, en la cual los sublevados fueron derrotados por las tropas leales al gobierno chileno. ${ }^{1}$

La importancia que tuvieron los acontecimientos señalados para comprender la situación de los emigrados peruanos en Chile, radica en el hecho de que estos participaron activamente en la Batalla del Barón. Ocurrió que ante los eventos ocurridos en Quillota, los militares peruanos que se encontraban en Valparaíso en calidad de emigrados, se organizaron y, dirigidos por el general Ramón Castilla (1797-1867) se plegaron a las tropas que defendían la ciudad contra los sublevados. $\mathrm{Si}$ bien militarmente su aporte fue modesto, lo transcendente de esa acción estuvo en el plano político. En efecto, el hecho de que los emigrados peruanos se sumaran a las fuerzas que defendían Valparaíso, demostró a las autoridades chilenas, lo que percibían, como el compromiso que aquellos tenían con el orden, la ley y el sentido libertador de la expedición que se preparaba en aquellos días contra la Confederación Perú-Boliviana (Serrano, 2011-2012: 153-160).

Esos acontecimientos sellarían una comunidad de ideas en torno a los principios republicanos entre

1 La versión inicial de este artículo fue redactada como trabajo final del curso Seminario de Historia de América Andina dictado por la Dra. Scarlett O'Phelan de la Maestría en Historia de la Pontificia Universidad Católica del Perú. Los contenidos son de mi entera responsabilidad. los emigrados peruanos y el gobierno chileno. Desde este punto de vista, la participación en la Batalla del Barón fue un hito clave en la historia y el destino de los emigrados peruanos. Se cerraba, de esta forma, un ciclo iniciado casi un año antes, en 1836, en el que los emigrados, a través de la prensa, habían tenido no solo que criticar y cuestionar a la Confederación Perú-Boliviana, sino también elaborar un discurso para explicar y legitimar el papel que ellos cumplían en la lucha contra la misma y sobre su pedido de una intervención chilena en el Perú, una patria a la cual pertenecían.

\section{Introducción}

El objetivo del artículo es estudiar el discurso político elaborado por los emigrados peruanos radicados en Chile entre 1836 y 1837. Ese discurso se elaboró entre junio de 1836 y los meses previos al inicio de la primera expedición restauradora en 1837. Se busca comprender la forma cómo los emigrados justificaron tanto su lucha contra la Confederación Perú-Boliviana como el apoyo que brindaron a la intervención militar chilena. En ese sentido se plantea que el discurso de los emigrados peruanos formó parte de una lucha política, en la cual coexistieron en permanente tensión dos ideales republicanos: el patriótico cívico y el nacionalista.

Para este trabajo se han formulado dos interrogantes. En primer lugar, se trata de conocer, ¿cuál fue la estrategia discursiva que emplearon los emigrados peruanos para legitimar, es decir, explicar y defender su postura? En segundo lugar, se busca saber qué líneas argumentativas estaban presentes en esa estrategia discursiva.

El presente artículo tiene como un importante referente el trabajo de Juan Carlos Arellano sobre los emigrados a los que él denomina los proscritos (Arellano, 2011). El investigador chileno estudia la participación de los emigrados peruanos en la formación de la opinión pública chilena durante la Confederación Perú-Boliviana. La principal diferencia entre el trabajo de Arellano y el presente texto consiste en que el primero analiza el discurso de los emigrados contra la Confederación, mientras que aquí nos centramos en el estudio del discurso de los emigrados para legitimar su propia postura. 
En ese mismo sentido, esta investigación se ha desarrollado partiendo de la lectura de la bibliografía especializada. Luego como fuente primaria se ha usado la prensa escrita de la época, eligiendo el semanario $E l$ Intérprete como la principal fuente.

\section{Los emigrados peruanos}

Los llamados emigrados, exiliados o proscritos fueron principalmente aquellos militares, políticos e intelectuales que, entre 1836 y 1837 , tuvieron que salir del Perú por voluntad propia o movidos por circunstancias adversas. La principal razón de su salida del Perú fue la oposición al gobierno del mariscal Andrés de Santa Cruz y la persecución que este implementó contra ellos. La mayor parte de los emigrados habían sido partidarios y colaboradores del general Felipe Santiago Salaverry (1806-1836). Los destinos iniciales de los emigrados fueron Ecuador, Chile y Costa Rica, aunque desde fines de 1836 y, a lo largo del ańo 1837, el grupo más importante y activo se concentraría en el puerto chileno de Valparaíso. El conjunto de emigrados peruanos estaba formado por personas de diversos estratos sociales, aunque la cantidad total de integrantes es desconocida, el grupo de líderes, entre políticos, intelectuales y militares, parece haber sido alrededor de sesenta personas.

A su llegada a Chile, la recepción favorable que tuvieron los emigrados por parte del gobierno de ese país, no fue un impedimento para que surgieran disputas o abiertas luchas entre ellos. Así, los grupos o facciones que se formaron en Chile fueron dos. Por un lado, estaba el grupo de los teóricos autoritarios y, por otro, el de los militares autoritarios. Los teóricos autoritarios fueron aristócratas e intelectuales, aunque también había militares. Destacaban entre ellos Felipe Pardo y Aliaga (1806-1868), el coronel Mariano Ignacio Vivanco (1806-1873) y Andrés Martínez (1795-1856), entre otros. El grupos de los militares autoritarios estaba formado por militares, aunque también habían civiles e intelectuales. Los más prominentes fueron el general Agustín Gamarra (1785-1841) y civiles como Juan Antonio Bujanda (1792-1836) y Bonifacio Lasarte. Otros, como los generales Ramón Castilla y Antonio Gutiérrez de la Fuente (1796-1878), permanecieron inicialmente al margen de las tensiones entre las dos facciones (Villanueva, 1963-1965: 34-37).
Si bien todos ellos estaban unidos por el objetivo de derrocar a Santa Cruz y poner fin a la Confederación Perú-Boliviana, las causas de sus diferencias eran diversas. Según las interpretaciones historiográficas tradicionales, las motivaciones de las luchas entre emigrados fue el "factor político", entendido como las rivalidades entre caudillos (Villanueva, 1963-1965: 8687). Por su parte, los estudios más recientes plantean como causa de las rivalidades las posturas opuestas que tenían respecto a los ideales y valores políticos. Así, unos fueron afines a un nacionalismo cercano a la tradición y, otros, lo eran a un republicanismo de corte más moderno (Arellano, 2011: 51-52).

Ahora bien, ya instalados en Chile, los emigrados peruanos se volcaron a ganarse el apoyo de las autoridades por medio de reuniones con los líderes del gobierno chileno y, asimismo, buscaron influir en la opinión pública por medio de sus publicaciones. Su objetivo era lograr que el gobierno chileno tomara la decisión de iniciar una guerra contra la Confederación. Sin embargo, la situación de los emigrados en Valparaíso no fue sencilla. Las dificultades que enfrentaban tenían que ver con las rivalidades entre ellos mismos, lo lejos que estaba el Perú, los limitados recursos con que contaban, los ataques que recibían en la prensa de los partidarios de la Confederación y, sobre todo, los cuestionamientos que recibían de algunos sectores de la clase política y el gobierno chileno, los cuales aún eran escépticos en iniciar una guerra contra la Confederación.

Sería en ese contexto político, inicialmente difícil para los emigrados peruanos radicados en Chile, que sus líderes tuvieron que legitimar en la prensa, tanto su rol en la lucha contra la Confederación Perú-Boliviana, como su pedido de una intervención chilena contra el Perú.

\section{La importancia del estudio de los emigrados}

Existen varias razones por las cuales es importante el estudio de un tema vinculado a la historia de la Confederación Perú-Boliviana. En primer lugar, está la naturaleza misma del hecho histórico. En ese sentido los años transcurridos entre 1836 y 1839, en los cuales la Confederación Perú-Boliviana estuvo vigente, constituyen una coyuntura histórica de una intensa dinámica política experimentada en un tiempo muy breve. Esta característica brinda la oportunidad 
de observar, en una situación límite, los esfuerzos realizados por parte de los emigrados y sus partidarios por construir un discurso político, que exprese no solo la animadversión por el rival político y militar, sino sobre todo sus concepciones, valores e ideales políticos.

Una segunda razón es de corte historiográfico. En la bibliografía especializada sobre la Confederación Perú-Boliviana $^{2}$ existen pocos trabajos sobre los emigrados peruanos. Aparte de la mención clásica a los emigrados realizada por Jorge Basadre (2002 [1930]: 105 y 114), es muy poco lo que se ha escrito al respecto. En los años sesenta se publicó el trabajo de Elena Villanueva (1963-1965), que sigue siendo el texto más amplio y detallado sobre los emigrados peruanos. Villanueva estudia, desde una visión clásica de la historia política, las pugnas entre los emigrados peruanos, radicados tanto en Chile como en Ecuador. Señala que hubo dos grupos: los militares autoritarios y los teóricos autoritarios. Aborda también otros temas como los motivos de la emigración, la preponderancia de uno y otro grupo, y 1 eptos y las razones morales de la guerra. Debemos señalar que estas últimas publicaciones se enmarcan en un enfoque de historia política, más atento a la cultura política, los discursos y el uso de la prensa escrita como fuente clave en la reconstrucción de los hechos históricos. Por otro lado, un tercer trabajo publicado hace algunos años es el de Laura Sánchez (2011-2012). Sánchez estudia el papel que jugaron los emigrados en la derrota de la

2 La historiografía sobre la Confederación Perú-Boliviana no es muy extensa. Principalmente, hay textos elaborados en los dos países involucrados, así como en Chile. En el Perú, algunos de los estudios clásicos fueron publicados por José de la Riva Agüero, La unión Perúboliviana: programa razonado. Obras completas. Tomo VII. Lima: Pontificia Universidad Católica e Instituto Riva Agüero, 1971, pp. 179189 y Jorge Basadre, Reconsideraciones sobre el problema histórico de la Confederación Perú-Boliviana, Alberto Flores-Galindo (editor), Independencia y Revolución, 1780-1840. Lima: IEP, 1987, vol.2. pp. 295-331. En la última década, la Confederación ha vuelto a llamar la atención de los historiadores peruanos y chilenos. Tres ejemplos sobre este renovado interés son la publicación, el año 2007 y como parte de los nuevos enfoques de la historia política, del artículo de Ana María Stuven titulado La palabra en armas: Patria y nación en la prensa de la guerra entre Chile y la Confederación Perú-Boliviana, 1835-1839, en el libro editado por Carmen Mc Evoy y Ana María Stuven, La república peregrina: hombres de armas y letras en América del Sur, 1800-1884. Lima: Instituto Francés de Estudios Andinos e Instituto de Estudios Peruanos, pp. 407-441. Por su parte el libro Guerra, región y nación: la Confederación Perú-Boliviana 1836-1839. Santiago de Chile: Centro de Investigaciones Diego Barros Arana, 2009, editado por Carlos Donoso y Jaime Rosenblitt, constituye un ejemplo de una obra colectiva de historiadores peruanos y chilenos. Más recientemente la publicación, el ańo 2012, del tomo XLV de la Revista Histórica, dedicada casi por completo a la Confederación, muestra el reciente y relativo interés por este hecho histórico.
Confederación Perú-Boliviana y la principal razón que tuvieron para oponerse al proyecto del mariscal Andrés de Santa Cruz (1792-1865). Señala que esa razón fue "que dejaron de lado los intereses nacionales; (...) estaban cegados por intereses regionales y personales" (Sánchez, 2011-2012: 135). ${ }^{3}$

Se concluye que en general la bibliografía sobre los emigrados no solo es escasa, sino que, en el conjunto de los estudios sobre la Confederación Perú-Boliviana, el tema de los emigrados ha sido tradicionalmente marginal, por lo cual, sigue siendo un tema pendiente la elaboración de una narrativa sobre la historia de los emigrados que visibilice los acontecimientos, hitos y actores involucrados entre 1836 y 1839 . Estos vacíos en la historia de los emigrados también se nota en que se desconoce quiénes eran. Así, fuera de algunos de sus líderes, como por ejemplo Ramón Castilla, no se conoce quiénes eran exactamente los civiles y militares de perfil más modesto que integraban el conjunto de los emigrados. De igual forma, más allá de las rivalidades entre facciones de caudillos, los intereses nacionales y personales en juego, o el temor a la hegemonía boliviana, la historiografía especializada no ha presentado explicaciones alternas que ayuden a comprender las motivaciones que llevaron a un grupo de militares y políticos peruanos a apoyar la guerra de Chile contra la Confederación. En contraste, solo en los últimos ańos se ha comenzado a explorar otros aspectos sobre la historia de los emigrados como, por ejemplo, los discursos políticos que se elaboraron en aquellos dramáticos años.

\section{Referentes conceptuales}

Para comprender la naturaleza de los discursos políticos aquí estudiados se considera necesario tomar en cuenta tres ejes de análisis. Estos ejes han sido formulados por diferentes autores para el estudio de los diversos discursos políticos que surgieron en el contexto de la Confederación Perú-Boliviana.

El primer eje analítico consiste en tomar en cuenta que en las décadas del veinte, treinta y cuarenta del siglo XIX en Hispanoamérica se fue modelando una

3 En su trabajo Laura Sánchez explica la postura asumida por los líderes de los emigrados como resultado de intereses políticos y personales. En contraposición, en este artículo, se considera que siendo aquella una razón, existen otras de mayor importancia como, por ejemplo, los ideales o proyectos que formaban parte de la cultura política de la época. 
concepción de nación que pasó por varias etapas. Empezó como un ideal de nación hispana, evolucionó hacia otro de nación americana regional y, finalmente, culminó en una naciente idea de nación circunscrita a los ámbitos territoriales de las nacientes repúblicas, emergiendo de esta forma, por ejemplo, el ideal de nación peruana, boliviana, chilena, etc. En esa trayectoria las tensiones entre los proyectos, que Lucena y Urorozqui llaman, globalización y singularización fue algo permanente. Los proyectos de globalización buscaron dar forma a naciones continentales, mientras que los de singularización estaban más atentos a las realidades e identidades regionales (Lucena y Ururozqui, 2003).

El segundo eje de análisis consiste en plantear que, en aquellas mismas décadas, en la mentalidad y el lenguaje político de las élites hispanoamericanas existían dos proyectos republicanos en conflicto. Uno basado en el patriotismo político y cívico y, el otro, sustentado en un nacionalismo histórico y cultural (Arellano, 2011: 52; Stuven, 2007: 417-418). Como parte de estos proyectos republicanos, los conceptos de patria, nación, república y otros adquirieron diversos significados y usos. El tercer eje consiste en considerar que los discursos también expresaron las rivalidades entre los caudillos, así como los intereses comerciales y geopolíticos de los gobiernos involucrados. Tomar en cuenta estos ejes analíticos en el estudio de los discursos sobre el rol de los emigrados peruanos en Chile, puede brindar referentes para comprender los proyectos e ideales políticos subyacentes.

Finalmente, hay que señalar que tratar de comprender los discursos de los emigrados, ubica este trabajo en el plano de la historia política y más, específicamente, en el análisis de la cultura, las ideas, las estrategias discursivas y los conceptos políticos. Esta precisión es importante, pues reconociendo que la lucha de los emigrados y del gobierno chileno contra la Confederación Perú-Boliviana tuvo importantes razones comerciales, políticas y geopolíticas, el estudio que aquí se realiza es sobre el discurso político.

\section{Dos proyectos políticos}

A partir de los referentes conceptuales señalados se desarrolla el argumento de que las posiciones en favor o en contra de la consolidación de la Confederación Perú-Boliviana estaban, fundamentalmente, asociadas a las tensiones entre dos proyectos que en aquellos momentos formaban parte de la cultura política en América Latina. Por un lado, los proyectos integradores que tenían la intención de formar grandes unidades políticas y territoriales. De otro lado, proyectos mucho más regionales que buscaban la conformación de espacios que hoy reconoceríamos como nacionales. Según este último proyecto, la unión del Perú y Bolivia, con hegemonía de este último país, era un contrasentido histórico ante el peso, cada vez mayor, de las dinámicas de formación de las identidades nacionales tanto de bolivianos, chilenos y peruanos.

De esta forma, los argumentos de los emigrados y los del gobierno chileno pertenecían a un lenguaje político republicano de tipo patriótico cívico, el cual sería el común denominador y, gradualmente, brindaría legitimidad a los propios emigrados ante ese gobierno. Junto a este proceso discursivo, la relación entre los emigrados y el gobierno chileno se selló con la demostración práctica de que los emigrados estaban comprometidos con los ideales y las instituciones republicanas. Esa demostración fue la participación peruana en la Batalla del Barón el 6 de junio de 1837 (Serrano, 2011-2012: 159).

Así, los discursos políticos sobre el papel de los emigrados no solo obedecían a intereses políticos personales, sino que reflejaban proyectos políticos en disputa. De esta forma, la oposición de los emigrados a la Confederación no respondió solo a rivalidades caudillistas o un sentimiento antiperuano, sino también a los ideales e imaginarios de la cultura política de la época.

\section{Discurso legitimador del papel de los emigrados}

Como se ha señalado, la legitimación que tuvieron que realizar los emigrados, no solo pasaba por atacar a la Confederación, sino que había que explicar y justificar el rol que ellos tenían y, sobre todo, el pedido de una intervención del gobierno chileno contra la Confederación y, en última instancia, contra el Perú, es decir su patria. Buena parte de ese esfuerzo de legitimación estuvo concentrado en responder a las críticas y cuestionamientos que recibían.

Desde su llegada a Valparaíso, el papel de los emigrados fue objeto de crítica por parte de los partidarios de la Confederación y de la propia prensa chilena. Las críticas de los partidarios del proyecto 
confederado se expresaban a través de publicaciones como El Eco del Protectorado, El Telégrafo de Lima y El Eco de Socabaya. Estos medios escritos abordaban diversos temas en el marco de un discurso de tipo nacionalista. En ese discurso, la nación era entendida como la unidad espiritual y cultural de un pueblo y sus enemigos eran la contaminación cultural, la heterogeneidad, la impureza racial y la desunión (Arellano, 2011: 52). Ahora bien, sobre el rol de los emigrados, señalaban que estaban cometiendo traición, que atentaban contra sus pueblos y que no podían ser perdonados. Frente a estas críticas y cuestionamientos, los emigrados peruanos en Chile elaborarían un discurso legitimador expresado en varios periódicos, entre ellos, El Intérprete.

En este punto, debido a que se usará como fuente primaria el semanario El Intérprete, es necesario resaltar algunas características de la prensa escrita de la época de la Confederación Perú-Boliviana. Una primera característica fue el rol político que tuvo la prensa desde la época de la independencia. A través de ella, los diversos actores políticos buscaban influir y ganar a la opinión pública hacia sus causas. De alguna forma, la prensa era vista como un arma necesaria y decisiva en los conflictos. La coyuntura de la Confederación Perú-Boliviana no escapa a esta tendencia. Otra característica fue la fluida y amplia circulación que tenían los periódicos en aquella época. Destaca y llama mucho la atención la libertad con que se publicaban y los ámbitos territoriales a los cuales esas publicaciones podían llegar. Esto se nota, por ejemplo, en la llegada al puerto de Valparaíso de publicaciones periódicas desde diversas ciudades de la Confederación y viceversa.

Una tercera característica fue el ejercicio de la crítica que una publicación hacía contra otra. Es muy frecuente encontrar reseńas, comentarios y respuesta a otras publicaciones. Buena parte del esfuerzo de los redactores no solo estaba en informar e influir en los lectores, sino también en deslegitimar a otros periódicos que buscaban lo mismo. Finalmente, también se debe destacar lo coyuntural de la mayoría de las publicaciones de aquellos ańos. Con pocas excepciones, los periódicos se seguían publicando más allá de algunos pocos meses.

Justamente, en el contexto de la Confederación Perú-Boliviana vieron la luz muchas publicaciones a favor y en contra de la misma. Publicaciones a favor de la Confederación fueron, entre otras, El Eco del Protectorado, El Telégrafo de Lima, El Eco de
Socabaya y El Boliviano de Chuquisaca. Por su parte, las más importantes publicaciones en contra de la Confederación fueron La Aurora Peruana, El Popular, La Bandera Bicolor, El Eventual y El Intérprete, la mayoría de ellas eran publicaciones de los emigrados peruanos en Chile.

En general, la prensa contraria a la Confederación en Chile se concentraba principalmente en cuestionar a Santa Cruz. Así, plantearon que Santa Cruz ponía en peligro la seguridad americana. Lo acusaban de no respetar los tratados, por ejemplo, el Tratado de Amistad, Comercio y Navegación; de manejar a su antojo la política; de encabezar un gobierno tirano y de su falta de honradez. De igual forma, se comenzaron a formar determinadas ideas en la opinión pública chilena como, por ejemplo, la idea no probada de que Santa Cruz deseaba expandir la Confederación a Chile y Ecuador.

La elección de El Intérprete para conocer el discurso de los emigrados se sustenta en varios criterios. En primer lugar, fue la publicación que más larga vida tuvo. Se publicó a lo largo de diez meses entre 1836 y 1837. En segundo lugar, fue patrocinada por Felipe Pardo y Aliaga, uno de los más representativos emigrados peruanos en Chile, quien, además, fue su principal redactor. En tercer lugar, El Intérprete se publicó en un momento en que la opinión pública chilena aún no tenía una idea formada sobre las implicancias que tenía para ese país la materialización de la Confederación y, por lo tanto, el periódico tuvo que luchar contra la corriente en su intento por formar una opinión pública favorable a la intervención chilena. En cuarto lugar, el periódico dejó de publicarse pocos meses antes del motín de Quillota, suceso que definiría positivamente la suerte de los emigrados.

El Intérprete fue un periódico publicado semanalmente en Chile. Su primer número salió a la venta el 13 de junio de 1836 y, el último, se publicó el 18 de marzo de 1837 . Tuvo en total treinta números. En su última edición se publicó una carta titulada "Al público de Chile" explicando el sentido y objetivo que había tenido la publicación. ${ }^{4}$ El Intérprete estaba organizado en secciones. Las más importantes y frecuentes eran las siguientes: "El Intérprete", era una especie de columna editorial; "Perú", con noticias del Perú; "Bolivia" con información sobre ese país; "Remitido", donde se presentaban cartas o información

$4 \quad$ El Intérprete, número 30, 18 de marzo de 1837. 
de contenido político enviadas al periódico por los lectores; "Interior", con noticias de Chile; "Esteriores" (sic), con noticias de países de América Latina y del mundo; "Post-Scriptum", sección donde los redactores del periódico contestan a sus críticos; "Variedades", con diversos temas: y, finalmente, la sección "Avisos", que era la única sección que no tenía contenido político, allí se presentaban avisos sobre ventas, remates o alquileres mandados por los suscriptores del periódico. También se publicaba en algunas secciones, versos o letrillas de corte político y satírico. Finalmente, se debe señalar que no siempre las secciones estaban en este orden y tampoco salían publicadas en todos los números. ${ }^{5}$

¿Cómo los emigrados legitimaron su rol en la lucha contra la Confederación y su pedido de una intervención chilena en su propio país? ¿Cuál era su estrategia discursiva? ¿De qué forma El Intérprete expresa esta legitimación? Una lectura atenta de los treinta números publicados de El Intérprete permite identificar las principales líneas de la estrategia discursiva que esta publicación elaboró para legitimar el rol de los emigrados peruanos.

Las principales líneas de la estrategia discursiva seguida por El Intérprete fueron las siguientes: explicitó siempre su postura política y no buscó disfrazarla o hacerla pasar por objetiva; argumentó permanentemente en torno a lo que Juan Carlos Arellano ha llamado las razones morales de la guerra (Arellano, 2011: 51); respondió activamente las críticas que otras publicaciones hicieron a la postura de los emigrados; planteó reiteradamente la idea de que al asumir su postura, los emigrados solo estaban ejerciendo su derecho a la libertad de opinión; y presentaron la lucha de los emigrados como una lucha compartida con la república y el pueblo chileno.

La primera línea que siguió la estrategia discursiva de El Intérprete fue hacer explicita su postura sobre la Confederación Perú-Boliviana. Los redactores del periódico, desde el primer número, señalan que «el título modesto que hemos escojido (sic) manifiesta

$5 \quad$ El Intérprete. Santiago de Chile: Imprenta de la Opinión, números 1-21 (1836) y 22-30 (1837). Colección Félix Denegri Luna, Archivo Histórico del Instituto Riva Agüero de la Pontificia Universidad Católica del Perú. Otro periódico que los emigrados publicaron fue La Bandera Bicolor. Valparaíso: Imprenta de la Bandera. Números 2-5 (1837). Sin embargo, en la Colección Félix Denegri Luna solo se han hallado cuatro números de esta publicación. Además, en los números leídos, La Bandera Bicolor se concentra en criticar a la Confederación y no se han encontrado intentos de explicar la postura de los emigrados. Estas razones nos han llevado a priorizar para este trabajo el periódico El Intérprete. que no tenemos pretensiones á la tiranía de la opinión. Nuestros escritos no tendrán el carácter de dogmas, sino de meras interpretaciones». ${ }^{6}$ Con estas palabras el periódico declara que su objetivo es influir y modelar en la opinión pública.

De igual forma, como ya hemos señalado, el 18 de marzo 1837 se publicó el último número del periódico. Allí vio la luz una carta de despedida titulada "Al público de Chile". ${ }^{7}$ En ella se señala las razones por las cuales se había publicado El Intérprete y que, justamente, al estar en camino en esos momentos la intervención chilena contra la Confederación, la publicación llegaba a su fin. Al respecto, en el semanario se afirma en primera persona «coincidir mi despedida por sucesos importantes, que marcan una época notable en la historia de la América». ${ }^{8}$

Esta militancia política que tuvo El Intérprete también lo llevó a criticar las posturas pasivas ante los eventos políticos. Es en ese sentido, que se debe entender la crítica del periódico a lo que llama la «inacción». Para los redactores parece no haber peligro más grave para las repúblicas que los pueblos sean observadores pasivos de los eventos en los que está en juego su destino.

El Intérprete desarrolló una segunda línea en su estrategia discursiva. Esta consistió en explicar en sus páginas lo que podríamos llamar las razones morales de la guerra que los emigrados exigían. El razonamiento de que hay guerras moralmente justas porque en ellas se lucha contra la tiranía y por la defensa de determinados valores, está presente a lo largo de los números de $E l$ Intérprete.

En ese sentido, la publicación compara a Santa Cruz con tiranos de la historia y conquistadores, y esa condición es la razón por la cual esta guerra contra la Confederación es justa. Esto queda en claro en la siguiente cita donde los redactores de El Intérprete reseñan y hace suyas las palabras del periódico chileno El Minero de Coquimbo:

La alarma está en todas partes. La discordia parece querer huir para reconciliar los espíritus. Hay un entusiasmo general para tomar parte en la cruzada republicana que va a armarse contra el moderno Soldan y sus Soidas. ¡Quiera la suerte que esta guerra si se emprende por tan justa causa, arranque para siempre de raíz del suelo americano, los vástagos

El Intérprete, número 1, 13 de junio de 1836, p. 1.

El Intérprete, número 30, 18 de marzo de 1837, p. 4.

El Intérprete, número 30, 18 de marzo de 1837, p. 4. 
bastardos e inmundos que quisiesen remedar a los tiranos y conquistadores!

La tiranía del protector también, según El Interprete, se nota en las intenciones monárquicas de Santa Cruz. $\mathrm{Al}$ respecto, el semanario señala que «el año que viene dará un paso más el congreso (...) convertirán a Simón Andrés Rafael en príncipe de Socabaya, como quien dice príncipe de Asturias». ${ }^{10}$

Asimismo, en el número 18, El Intérprete hace una reconstrucción histórica de los sucesos que han llevado, finalmente, a las autoridades chilenas a decidirse por la guerra contra la Confederación. ${ }^{11}$ Este relato trata de racionalizar la secuencia de los hechos ocurrido durante los meses previos a la declaración de guerra contra la Confederación y demostrar que esta ha sido la respuesta ante las hostilidades, las ofensas y los agravios recibidos reiteradamente.

Una tercera línea que siguió la estrategia discursiva de El Intérprete fue responder permanentemente a los cuestionamientos que se hacían a los emigrados. Estas respuestas tuvieron que ser elaboradas frente a las críticas, tanto de los partidarios de la Confederación como de la propia prensa chilena.

En los primeros números de El Intérprete se puede apreciar cómo el periódico debe comentar y responder a los cuestionamientos de la prensa chilena. Periódicos como El Araucano, El Mercurio y El Barómetro de Chile recomendaban y exigían a El Intérprete moderación en sus críticas y su requerimiento de una intervención chilena contra la Confederación. Las respuestas del diario de los emigrados se dan en los primeros números, en la sección "El Intérprete", y en números posteriores en otras secciones.

Así, en el primer número, El Intérprete ya había muy sutilmente comunicado en unos sonetos lo que pensaba de esas otras publicaciones: «iY cómo escribo yo sin saber jota?... / ¡Gran escollo por cierto en el que doi / Cuando veo que escribe tanto idiota!» ${ }^{12}$

Una de las primeras respuestas que el semanario publica es contra El Mercurio de Valparaíso. Con ánimo de polemizar, El Intérprete señala que el periódico chileno le critica "cierto grado de vehemencia que no es siempre conveniente a los escritos periódicos» y le «aconseja que hagamos 'resaltar en nuestras

9 El Intérprete, número 5, 11 de julio de 1836, p. 4.

10 El Intérprete, número 11, 24 de agosto de 1836, p. 2.

11 El Intérprete, número 18, 12 de octubre de 1836, p. 1.

12 El Intérprete, número 1,13 de junio de 1836, p. 1. producciones un enérgico pero frío raciocinio'». ${ }^{13} \mathrm{~A}$ esa sugerencia, el semanario responde que:

a lo primero diremos que desearíamos saber si desde Aristóteles hasta nuestros días ha habido algún preceptista que enseñe que la vehemencia no es siempre conveniente a los escritos periódicos cuando discuten sobre los actos gubernativos de un poder extraño. ${ }^{14}$

En otro número, El Intérprete aclara a El Eventual y le pide que «déjese, pues, hermano de solicitar la intervención del gobierno en nuestros escritos, y cíńase solo a continuar examinando su bendita desinteligencia: pero sin andarse por las ramas». ${ }^{15}$ Estas respuestas también las tiene contra El Mercurio de Valparaíso. Sobre él dice que:

estamos con nuestro hermano mayor el Mercurio de Valparaíso como los hijos de Edipo. Nos es verdaderamente doloroso dar escándalos con nuestras disputas: pero desgraciadamente pertenecemos a la gritadora familia de periodistas. ${ }^{16}$

Incluso, en un número posterior, El Intérprete se burla del cierre de El Barómetro de Chile al decir que «cumplimos con la dolorosa obligación de anunciar al público, enlutando nuestras columnas, que el miércoles 20 del corriente falleció en esta ciudad nuestro amado hermano El Barómetro de Chile». ${ }^{17}$ Para luego con el mismo humor y sarcasmo acotar:

Sus últimas palabras fueron éstas: 'Hemos exigido moderación y principios, y se nos ha clasificado de demagogos, prodigándosenos los mayores insultos y ostentando siempre una personalidad refinada. A todo hemos puesto la paciencia y más paciencia. ¡Que sacrificios no merece una patria tan amada!' ${ }^{18}$

Los comentarios y respuestas a la prensa chilena, que cuestionaba el rol de los emigrados, estuvieron presentes en la fase inicial de la publicación durante el año 1836. Luego de la declaración de guerra contra la Confederación, estas respuestas prácticamente desaparecen de las páginas de El Intérprete. A partir de 1837, van cobrado fuerza las respuestas que el periódico

13 El Intérprete, número 2, 20 de junio de 1836, p. 1.

14 El Intérprete, número 2, 20 de junio de 1836, p. 1.

15 El Intérprete, número 14, 14 de setiembre de 1836, p. 3.

16 El Intérprete, número 6, 18 de julio de 1836, p. 1.

17 El Intérprete, número 7, 25 de julio de 1836, p. 3.

18 El Intérprete, número 7, 25 de julio de 1836, p. 3. 
tuvo que hacer contra los ataques de la prensa de la propia Confederación Perú-Boliviana. Un ejemplo representativo de estas disputas se da con El Estandarte de Lima. En su número 26, El Intérprete señala que:

El Estandarte, periódico de Lima, que (como debe presumirse sin formar un juicio temerario) es también eco del protectorado, contiene largas declamaciones contra la infidencia de los emigrados, que unen sus sentimientos a los de Chile en la guerra contra su señor natural el Gran Ciudadano, que velis nolis ha de ser en el lenguaje de aquellos periodistas la misma cosa que el Perú. Es imposible, exclama el Estandarte en un rapto de entusiasmo: no cabe reconciliación: ni el Perú ni ningún pueblo perdonará jamás a aquellos de sus hijos que se enrolen en filas extranjeras para combatirle. Convenido, carísimos colegas, los del Estandarte; pero como los emigrados no se enrolan en las filas que combaten al Perú, sino en las filas que combaten al que ha combatido y oprime al Perú, se sigue que el Perú no tendrá que perdonarles, sino que agradecerles. $\mathrm{Y}_{\text {¡cuenta con el principio! que os }}$ parte de medio a medio, si sois peruanos; a no ser que le modifiquéis con esta restricción, salvo el caso en que las filas extranjeras sean filas de Santa Cruz. ${ }^{19}$

Como se ve en la cita, la acusación que El Estandarte realiza contra los emigrados es la unión que hacen con Chile, con un gobierno extranjero, y que esa decisión de traicionar a su patria hace imperdonable su falta. La defensa de los emigrados es que ellos combaten no al Perú, sino a la tiranía que oprime a ese país.

Una cuarta línea discursiva sobre el rol de los emigrados, en la voz de El Intérprete, fue plantear reiteradamente la idea de que al asumir su postura, los emigrados solo ejercían un derecho: la libertad de opinión. En el discurso de los emigrados, la libertad es un valor republicano. La libertad es un principio universal, no es un valor particularista como el alma o la identidad. En el discurso de los emigrados, la libertad de opinión es una responsabilidad ciudadana y es intrínseca a las repúblicas. En ese sentido, se pueden encontrar en las páginas de El Intérprete defensas de la libertad de opinión que ellos, como extranjeros, tienen. Por ejemplo, en el número 12 de la publicación señalan que:

La constitución en su artículo 12 asegura a todos los habitantes de la republica la libertad de publicar sus opiniones por la imprenta, sin censura previa, y el

19 El Intérprete, número 26, 10 de febrero de 1837, p. 3. derecho de no poder ser condenados por el abuso de esta libertad, sino en virtud de un juicio en que se califique previamente el abuso por jurados, y se siga y sentencie la causa con arreglo a la ley.

Supongamos que efectivamente el editor del Intérprete sea un emigrado del Perú, aunque si ha estado en aquella república ha salido de ella libre y públicamente, y con pasaporte de las autoridades. ¿Por ser emigrado deja de ser habitante de Chile? ¿Por ser emigrado tiene algún otro código a que estar sujeto? ${ }^{20}$

Es muy claro el razonamiento del semanario. La libertad de opinar es un derecho garantizado por la ley y alcanza al ciudadano, incluso más allá de su nacionalidad. Esto es así porque las repúblicas defienden a los hombres, sean de uno u otro país, cosa que por cierto no hace Santa Cruz, según El Intérprete. Esta última afirmación queda en evidencia en las siguientes palabras:

Aplicando ahora el argumento a la publicación de nuestro periódico, el gobierno chileno no hace más que tolerar la libertad de imprenta que las leyes no le permiten reprimir, y el gobierno de Santa Cruz no puede con fundamento quejarse de una tolerancia que no puede ser caracterizada de agravio sino por los que como Santa Cruz se burlan de las leyes y de la justicia, y no tienen más reglas de operaciones que los antojos de su voluntad. ${ }^{21}$

Una quinta línea de la estrategia discursiva desarrollada por El Intérprete es la idea recurrente de que la lucha de los emigrados es una lucha compartida con la república y el pueblo chileno. Invocando una hermandad política republicana, señala que:

no podemos ser indiferentes a la suerte de nuestros hermanos, ni dejar de reportar ejemplos provechosos del examen detenido de sus alternativas políticas, de las causas que las originan y de los fatales resultados a que conducen. ${ }^{22}$

Esta comunidad entre peruanos y chilenos se explica así «no: Chile no ha sido jamás ni tiene porque ser enemigo del Perú: si hoy ha recibido agravios del gobierno de aquella república». ${ }^{23}$ Luego agrega que, incluso, la adversidad que significa la Confederación ha sellado las relaciones entre ambos pueblos:

20 El Intérprete, número 7, 25 de julio de 1836, p. 3.

21 El Intérprete, número 14, 14 de setiembre de 1836, p. 2.

22 El Intérprete, número 1, 13 de junio 1836, p. 1.

23 El Intérprete, número 10, 16 de agosto de 1836, p. 4. 
Los mismos esfuerzos de Santa Cruz, y de su instrumento el general Orbegoso, por romper los lazos de amistad entre Chile y el Perú, parece que no han servido sino para preparar un nuevo vinculo, más fuerte y más sangrado que los que han existido hasta ahora, a las relaciones de estos dos pueblos. ${ }^{24}$

Se puede apreciar cómo el periódico apela, como justificación a la relación entre ambas naciones, a la idea de la comunidad o gran patria americana, aunque como entidades políticas republicanas. Esto hay que entenderlo en el contexto de tránsito que se vive sobre las ideas de patria. Según Lucena y Ururozqui, en el contexto de la Confederación Perú-Boliviana hay una visión política de tránsito del ideal de la nación española y americana hacia la nación peruana, boliviana o chilena (Lucena y Ururozqui, 2003: 422). En ese contexto, las lealtades a las naciones es algo que se está redefiniendo. Se está pasando de la patria americana a las patrias locales. Desde este punto de vista, los discursos a favor o en contra de los emigrados que se expresan en la prensa no están condicionados por las patrias locales, sino que hay que entenderlos justamente en el tránsito de las lealtades al proyecto de la patria americana hacia las patrias locales aún en germinación.

Los emigrados pertenecen a una generación de políticos, militares e intelectuales que antes que peruanos, chilenos o bolivianos, son «americanistas que habían luchado unidos, por la independencia del Cono Sur». Solo esta perspectiva permite comprender el apoyo de los emigrados al gobierno chileno (Serrano, 2011-2012: 142).

La estrategia discursiva y los argumentos desplegados por los emigrados peruanos en Chile, con el objetivo de influir en la opinión pública y en el gobierno chileno, fueron importantes en la decisión de iniciar la guerra contra la Confederación PerúBoliviana. Sin embargo, las pocas resistencias que aún quedaban en esa misma opinión pública, en el gobierno y en algunos otros actores políticos, serían revertidas por un acontecimiento en que los emigrados peruanos también tendrían participación: el motín de Quillota.

\section{Más allá del discurso}

Los emigrados peruanos radicados en Chile no solo tendrían que defender su postura y declarar su

24 El Intérprete, número 10, 16 de agosto de 1836, p. 4. republicanismo con las palabras, tendrían que ir más allá de ellas. Fue la propia dinámica política chilena la que ofreció la oportunidad para que los emigrados probaran en la práctica su compromiso con la república chilena. La participación de los emigrados peruanos en la Batalla del Barón, hecho con la cual se debeló el motín de Quillota, fue un acontecimiento que marcó un antes y un después para los emigrados: demostró su compromiso con el orden republicano.

Ya con anterioridad al motín de Quillota, otros hechos habían sido los detonantes de la declaratoria de guerra contra la Confederación Perú-Boliviana en diciembre de 1837. La llamada expedición de Freyre contra el gobierno del presidente Prieto y la no ratificación por parte de la Confederación del Tratado de Amistad y Comercio, habían dado el pretexto para hacer oficial la guerra contra la Confederación. Pero, fue la Batalla del Barón la que galvanizaría a la opinión pública chilena y sellaría la relación entre los emigrados y el gobierno. Ponerse del lado de la ley y el Estado chileno durante el motín de Quillota y legitimar políticamente la acción interventora en el Perú, serían los aportes más importantes de los emigrados.

La relación entre emigrados y el gobierno de Santiago de Chile fue resultado, tanto de los intereses económicos y políticos comunes, como de compartir un lenguaje y conceptos legitimadores de la guerra de tipo republicano en su vertiente patriota cívica. La base de su argumentación fue permanentemente la invocación a los ideales de la república y la libertad.

\section{Conclusiones}

El discurso legitimador sobre el papel jugado por los emigrados peruanos en su lucha contra la Confederación Perú-Boliviana desarrolló una estrategia discursiva en la que se enfatizaron algunos temas. Formó parte de esa estrategia discursiva explicitar su postura política contra la Confederación, señalar las razones morales de la guerra, como también ha concluido Arellano (2011: 65), responder a los cuestionamientos sobre su rol, plantear la idea de que los emigrados solo ejercían el derecho de la libertad de opinión y presentar la lucha de los emigrados como una lucha compartida con la república y el pueblo chileno.

Ese discurso legitimador formó parte de una lucha ideológica, en la cual existieron dos ideales políticos que se expresaron en los discursos de la época, el 
republicano (connotación política) y el nacionalista (connotación cultural y étnica). El primero enarbolado por los emigrados y el gobierno chileno y el segundo por los partidarios de la Confederación.

Los emigrados fueron importantes en la lucha contra la Confederación, fundamentalmente, porque presentaron como legítimas las acciones armadas llevadas a cabo por el gobierno chileno. Crearon un discurso político, que precedió a las campañas restauradoras. En ese discurso la guerra de invasión contra el Perú, era una campaña militar que buscaba restaurar la libertad de la república peruana la que había caído bajo la tiranía de Santa Cruz.

\section{Archivos y Fondo Documentales}

Archivo Histórico del Instituto Riva Agüero, Colección Denegri Luna.

\section{Fuentes primarias}

El Intérprete. Santiago de Chile: Imprenta de la Opinión. Números 1-21 (1836) y 22-30 (1837).

La Bandera Bicolor. Valparaíso: Imprenta de la Bandera. Números 2-5 (1837).

\section{Referencias bibliográficas}

Arellano, Juan Carlos (2011). Los republicanos en armas: los proscritos, el gobierno y la opinión pública ante la Confederación Perú-Boliviana. Universum, Talca (Chile), Universidad de Talca, No 26, Vol. 2, pp. 49-66. Recuperado de https:/scielo.conicyt.cl/pdf/universum/ v26n2/art_03.pdf

BASADRE, Jorge (2002 [1930]). La iniciación de la república: contribución al estudio de la evolución política y social del Perú. Tomo segundo. Lima: UNMSM, Fondo Editorial.

BASADRE, Jorge (1987). Reconsideraciones sobre el problema histórico de la Confederación Perú-Boliviana. En Alberto
Flores-Galindo (ed.), Independencia y Revolución, 17801840. Vol. 2. Lima: INC, pp. 295-331.

Betancourt, Francisco (2011-2012). Norte versus sur: de noticias, desengaños y entusiasmos en la defensa de la Confederación Perú-Bolivia. Revista Histórica, Lima, Tomo XLV, pp. 279-304.

Donoso, Carlos y Jaime Rosenblitt, editores (2009). Guerra, región y nación: la Confederación Perú-Boliviana 1836-1839. Santiago de Chile: Centro de Investigaciones Diego Barros Arana.

Lucena, Manuel y Marta UrurozQui (2003). Lima vs. Valparaíso. El balance de poder en la América Andina. En Juan Maiguashca (ed.), Historia de América Andina. Quito: Universidad Andina Simón Bolívar, vol. 5, pp. 419-457.

Riva Agüero, José de la (1971). La unión Perú-boliviana: programa razonado. En Obras completas. Tomo VII. Lima: Pontificia Universidad Católica e Instituto Riva Agüero, 1971, pp. 179-189.

SÁncheZ, Laura (2011-2012). Adversarios políticos de la Confederación Perú-Boliviana desde la distancia. Revista Histórica, Lima, Tomo XLV, pp. 117-139.

Serrano, Gonzalo (2011-2012). Emigrados peruanos en Valparaíso durante la Guerra de Chile contra la Confederación Perú-Boliviana (1836-1839). Revista Histórica, Lima, Tomo XLV, pp. 141-162.

Stuven, Ana María (2007). La palabra en armas: Patria y nación en la prensa de la guerra entre Chile y la Confederación Perú-Boliviana, 1835-1839. En Carmen Mc Evoy y Ana María Stuven, (editores), La república peregrina: hombres de armas y letras en América del Sur, 1800-1884. Lima: Instituto Francés de Estudios Andinos e Instituto de Estudios Peruanos, pp. 407-441.

TejadA, Erick y Omar Tovar (2011-2012). Una nación en disputa: «El Yanacocha» y «El Ariete» durante la Confederación Perú-Boliviana. Revista Histórica, Lima, Tomo XLV, pp. 305-327.

Villanueva, Elena (1963-1965). La lucha por el poder entre los emigrados peruanos (1836-1839). Boletín del Instituto Riva-Agüero, Lima: Pontificia Universidad Católica del Perú, N.o 6, pp. 7-89. 